\section{Discussion}

Sclerosing lobulitis was first described by Soler and Khardori in 1984 in a group of patients with Hashimoto's thyroiditis, IDDM and cheiroarthropathy with histological similarity between breast tissue and thyroiditis. ${ }^{4}$ Fibrous mastopathy, diabetic mastopathy, and sclerosing mastitis are terms synonymous with sclerosing lobulitis. It is an uncommon condition associated with a raised ESR, CRP and normochromic normocytic anaemia. The histology is very similar to that of retroperitoneal fibrosis. Both conditions have a chronic inflammatory cell infiltrate with predominance of B lymphocytes and expression of HLA-DR antigen. Fibroblastic proliferation leads to hypocellular areas of keloid-like glassy collagen fibres. Autoimmune pathogenesis has been suggested. ${ }^{25}$ To the best of our knowledge, this is the first reported association between retroperitoneal fibrosis and sclerosing lobulitis of the breast. We feel all these conditions are clinical variants of SMF.

This case also illustrates how retroperitoneal fibrosis can present as an isolated pelvic mass and the requirement often of laparotomy to establish the diagnosis, relieve any obstructive nephropathy, and exclude malignancy such as lymphomas. Management remains controversial. Corticosteroids with surgical

1 Aylward GW, Sullivan TJ, Garner A, Moseley I, Wright JE. Orbital involvement in multifocal fibrosclerosis. $\mathrm{Br}$ Ophthalmol 1995;79:246-9.

2 Schwartz S, Strauchen JA. Lymphocytic mastopathy- an autoimmune disease of the breast? Am $f$ Clin Pathol 1990;93:725-30.

3 Anwar N, Taylor PM, Carrol RN, Ramsden RT, Merchan $\mathrm{M}$, Gokal R. An unusual case of retroperitoneal fibrosis. $\mathrm{Am}$ F Kidney Dis 1993;1:57-9.

4 Soler NG, Khardori R. Fibrous disease of the breast, thyroiditis and cheiroarthropathy in type 1 diabetes mellitus. Lancet 1984;1:193-5.

5 Parums DV. Aortic atherosclerosis: pathogenesis and local complications. In: McGee JO'D, Isaacson PG, Wright NA eds. Oxford Textbook of pathology, vol 2a. Oxford: Oxford eds. Oxford Textbook of pathology,
University Press 1992; pp 815-7.

\section{SMF: reported associations}

- mediastinal fibrosis

- maxillary sinus disease

- sclerosing cholangitis

- Riedel's thyroiditis

- retroperitoneal fibrosis

- Sjogren's syndrome

- sclerosing lobulitis

- pseudotumours of the orbit

- Hashimoto's thyroiditis

- IDDM

intervention in the form of ureterolysis and/or ureteric stenting is the most common approach. Corticosteroid therapy alone may relieve obstruction, but is by no means always effective. Uterolysis alone is associated with recurrence and the development of obstruction in the previously unaffected kidney. ${ }^{6}$ Immunosuppressants such as azathioprine and penicillamine have been used with variable success rates. ${ }^{7}$ The relapse rate after cessation of steroids has been studied by Baker $e t$ $a l$ in a series of 60 patients in which 10 patients relapsed after 5 years and a further five as late as 10 years, illustrating the need for long term follow-up. ${ }^{8}$

6 Baker LRI. Urinary tract obstruction. In: Weatherall DJ, Ledingham GG, Warrell DA, eds. Oxford Textbook of medicine, vol 3. Oxford: Oxford University Press, 1996; pp 3244-6.

7 Harreby M, Bilde T, Helin P, Meyhoff $\mathbf{H H}$, Vinterberg H, Nielson VA. Retroperitoneal fibrosis treated with methylpredisolon pulse and disease-modifying antirheumatic drugs Scand F Urol Nephrol 1994;28:237-42.

8 Baker LRI, Mallinson WJW, Gregory MC, Menzies EAD, Cattell WR, Whitfield HN. Idiopathic retroperitoneal fibrosis. A retrospective analysis of 60 cases. $\mathrm{Br} \quad \mathcal{f}$ Urol 1988;60:497-530.

\title{
Gastric rupture secondary to successful Heimlich manoeuvre
}

\author{
Arun Majumdar, P C Sedman
}

Department of Surgery, Hull Royal Infirmary, Anlaby Road, Hull HU3 2JZ, UK

A Majumdar

P C Sedman

Accepted 10 March 1998

\section{Summary}

A fatal case of gastric rupture following the Heimlich manoeuvre is reported. This life-threatening complication has only been reported previously in seven patients with a high mortality rate. All patients should be assessed immediately following this manoeuvre for any potentially lifethreatening complications.

Keywords: gastric rupture; Heimlich manoeuvre
The Heimlich manoeuvre is an essential first-aid resuscitative measure to relieve acute upper airway obstruction. Henry Heimlich first described this life-saving procedure in June 1974, after successfully carrying out experimental studies on animals. Within the first nine months, 162 lives were reported saved. Heimlich only encountered fractured ribs as a complication when the manoeuvre was improperly performed. Since then, however, a number of potentially fatal complications have been reported. We 


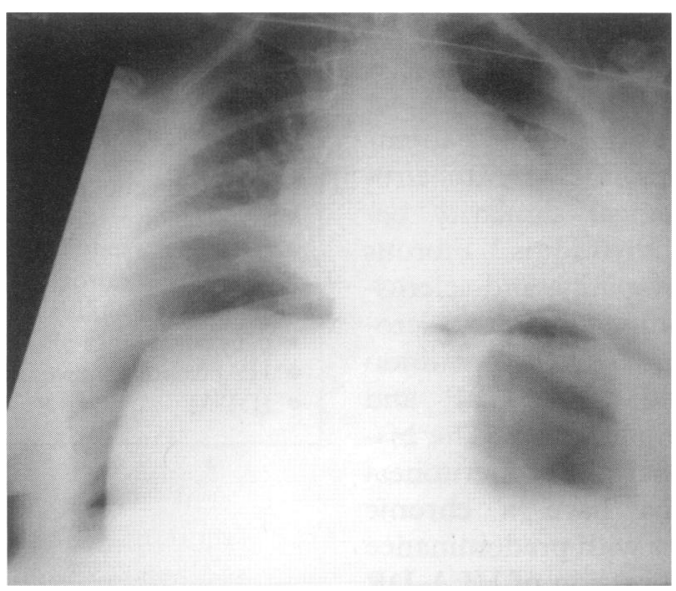

Figure Chest X-ray of the patient showing pneumoperitoneum

report a case of gastric rupture as a result of this procedure with fatal consequences.

\section{Case report}

A 57-year-old woman was brought to the resuscitation room by the paramedics after having choked on a pizza at home. A successful Heimlich manoeuvre had been performed, as had a period of cardiopulmonary resuscitation for an apparent apnoeic arrest. This was successful. During transfer to hospital, however, she vomited 1 litre of blood, partially aggravated by over anticoagulation for a metallic aortic valve.

Abdominal examination on arrival revealed a distended abdomen with a tender epigastrium, tympanitic to percussion. Bowel sounds were absent. Chest X-ray revealed pneumoperitoneum and fractured ribs on the right side and a clinical diagnosis of ruptured viscus was made (figure).

After fluid resuscitation and correction of clotting, surgery was performed within two hours of initial presentation. At laparotomy, pneumoperitoneum was confirmed. There was bruising along the lesser curve and a macronodular cirrhosis of the liver (probably alcohol related) was noted. Through an anterior gastrotomy, a full thickness $2 \mathrm{~cm}$ linear laceration was noted along the lesser curve of the stomach, with some mucosal laceration on the posterior wall of the stomach. There was no evident oesophageal perforation. The lesser curve laceration was repaired in two layers and reinforced with an omental patch. The mucosal laceration was also sutured.

1 Heimlich HJ. A life saving manoeuvre to prevent food choking. $\mathscr{f} A M A$ 1975;234:398.

2 Brunsting LA, Morton JH. Gastric rupture from blunt abdominal trauma. $\mathcal{F}$ Trauma 1987;27:887.

3 Yaiko RD, Seydel F, Trimble C. Rupture of the stomach Yajko RD, Seydel F, Trimble C. Rupture of the stom
from blunt abdominal trauma. $\mathcal{F}$ Trauma $1975 ; 15: 177$.

4 Visintine RE, Baick $\mathrm{CH}$. Ruptured stomach after Heimlich manoeuvre. FAMA 1975;234:415.

5 Croom DW. Rupture of stomach after attempted Heimlich manoeuvre. $\mathcal{F} A M A$ 1983;250:2602.

6 Cowan M, Bardole J, Desk A. Perforated stomach following the Heimlich manoeuvre. Am $\mathcal{F}$ Emerg Med 1987;5:121-2.

\section{Summary points}

- Heimlich manoeuvre is an effective resuscitative measure to relieve acute upper airway obstruction

- all patients should be assessed immediately following this manoeuvre for any potentially life-threatening complications

After initial excellent progress the patient became haemodynamically unstable 48 hours later necessitating an exploratory laparotomy for bleeding at which no cause was found for an intraperitoneal bleed. A further bleed occurred 48 hours later, this time intragastrically following secondary haemorrhage along the rupture site. Gastrointestinal endoscopy confirmed a normal oesophagus.

The patient gradually deteriorated over the next few days and it was not possible to wean her off the ventilator, despite full support. She finally succumbed as a result of a subendocardial myocardial infarction and bronchopneumonia 16 days after initial presentation.

\section{Discussion}

Gastric rupture following blunt abdominal trauma is extremely rare and has an incidence of less than $1.7 \% .^{2}$ Morbidity and mortality rate as a result of this injury are high $(47 \%)$, mostly due to intra-abdominal sepsis. ${ }^{3}$

Gastric rupture secondary to Heimlich manoeuvre has been previously documented in seven patients, ${ }^{4-9}$ three of whom ultimately succumbed to this injury. In all these cases the rupture was along the lesser curvature. Various hypotheses have been put forward to explain susceptibility of the lesser curve to this type of injury. Darke \& Bloomfeld ${ }^{10}$ reported that the lesser curve was more likely to tear because it has fewer mucosal folds and is therefore less elastic. Tearing of the gastric wall is produced due to gastric distension combined with a forceful increase of intra-abdominal pressure as a result of the Heimlich manoeuvre.

Our paper highlights yet again a rare complication of the Heimlich manoeuvre on a full stomach. The patient was initially resuscitated successfully but finally succumbed to complications, aggravated by her medical problems. Patients treated with the Heimlich manoeuvre should be assessed immediately after the procedure to enable prompt diagnosis and effective treatment of any complications.

\footnotetext{
7 Dupre MW, Silva E, Brotman S. Traumatic rupture of the stomach secondary to Heimlich manoeuvre. Am $\mathcal{F}$ Emerg Med 1993;11:611-2.

Med 1993;11:611-2.
8 Bintz M, Cogbill TH. Gastric rupture after the Heimlich manoeuvre. F Trauma 1996;40:159-60.

9 Van de Ham A, Large J. Traumatic rupture of the stomach after Heimlich manoeuvre. F Emerg Med 1996;8:713.

10 Darke SG, Bloomfield E. Case of complete gastric rupture complicating resuscitation. $B M \mathcal{F}$ 1975;3:414.
} 